\title{
Physician Perspectives on Incentives to Participate in Practice-based Research: A Greater Rochester Practice-Based Research Network (GR-PBRN) Study
}

\author{
Karen Gibson, MSEd, Peter Szilagyi, MD, MPH, Carlos M. Swanger, MD, \\ Thomas Campbell, MD, Thomas McInerny, MD, Joseph Duckett, Joseph J. Guido, MS, \\ and Kevin Fiscella, MD, MPH
}

Objectives: To understand factors associated with primary care physician research participation in a practice-based research network (PBRN) and to compare perspectives by specialty.

Methods: We surveyed primary care internists, family physicians, and pediatricians in Monroe County, New York, regarding their past experience with research and incentives to participate in practice-based research. We performed descriptive and tabular analyses to assess perceptions and used $\chi^{2}$ and analysis of variance to compare perceptions across the 3 specialties.

Results: The response rate was $33 \%$. The most frequently endorsed aspects of collaboration were the opportunity to enact quality improvement $(78 \%)$, contribution to clinical knowledge $(75 \%)$, and intellectual stimulation (65\%). Significant differences among the primary care specialties were found in 2 aspects: (1) internists were more likely to endorse additional source of income as "important," and family medicine physicians were more likely to cite the opportunity to shape research questions, projects, and journal articles as "important."

Conclusion: Physicians across all 3 specialties cited the opportunity to enact quality improvement and contribution to clinical knowledge as important incentives to participating in practice-based research. This supports the importance of strengthening the interface between research and quality improvement in PBRN projects. Further study is needed to assess reasons for differences among specialties if PBRNs are to become successful in research involving adult patients. (J Am Board Fam Med 2010;23:452-454.)

Keywords: Practice-based Research, PBRN, Primary Health Care, Community Health Systems

Practice-based research networks (PBRNs) are groups of practices that collaborate to study issues

This article was externally peer reviewed.

Submitted 29 June 2009; revised 13 August 2009; accepted 20 August 2009.

From the Center for Community Health (KG); the Department of Pediatrics (PS, TM); the Strong Children's Research Center (PS, TM); the Department of Medicine and Primary Care (CMS); the Department of Family Medicine (TC, KF); and the Department of Community and Preventive Medicine (JD, JJG), University of Rochester School of Medicine and Dentistry, Rochester, NY.

Funding: This publication was made possible by Grant no. UL1 RR024160 from the National Center for Research Resources (NCRR), a component of the National Institutes of Health (NIH), and the NIH Roadmap for Medical Research.

\footnotetext{
See Related Commentary on Page 440.
}

of importance to clinical care. Most involve primary care practices. PBRNs are important for translational research. ${ }^{1,2}$ Studies about practicebased research have primarily involved single disciplines such as pediatrics ${ }^{3}$ or family medicine $e^{4}$ and have not compared perspectives across disciplines.

In 2007, the University of Rochester's Clinical and Translational Science Institute, funded by a

Conflict of interest: none declared.

Disclaimer: The contents of this article are solely the responsibility of the authors and do not necessarily represent the official view of the NCRR or NIH. Information about the NCRR is available at http://www.ncrr.nih.gov/. Information on Re-engineering the Clinical Research Enterprise can be obtained from http://nihroadmap.nih.gov/clinicalresearch/overview-translational.asp.

Corresponding author: Karen Gibson, MSEd, Center for Community Health, University of Rochester Medical Center, 46 Prince Street, Rochester, NY 14607 (E-mail: Karen_gibson@urmc.rochester.edu). 
Table 1. Incentives Important to Monroe County Physicians for Participating in Research

\begin{tabular}{|c|c|c|c|c|c|}
\hline & $\begin{array}{c}\text { Total } \\
(\mathrm{n}=185)\end{array}$ & $\begin{array}{l}\text { Internal Medicine } \\
\quad(\mathrm{n}=70)\end{array}$ & $\begin{array}{l}\text { Family Medicine } \\
\quad(\mathrm{n}=37)\end{array}$ & $\begin{array}{l}\text { Pediatrics } \\
(\mathrm{n}=78)\end{array}$ & $P$ \\
\hline Intellectual stimulation & 65.4 & 60.0 & 64.9 & 70.5 & .41 \\
\hline Contribution to clinical knowledge & 75.1 & 75.7 & 70.3 & 76.9 & .74 \\
\hline Recognition from patients & 16.8 & 17.1 & 13.5 & 18.0 & .83 \\
\hline Recognition from colleagues & 21.2 & 18.8 & 29.7 & 19.2 & .36 \\
\hline Opportunity to enact quality improvement & 77.8 & 72.9 & 78.4 & 82.1 & .40 \\
\hline Change of pace & 31.0 & 30.0 & 27.8 & 33.3 & .82 \\
\hline Additional income source & 30.4 & 41.4 & 24.3 & 23.4 & .04 \\
\hline Interaction with colleagues around research issues & 52.4 & 45.7 & 54.1 & 57.7 & .34 \\
\hline $\begin{array}{l}\text { Method to gain continuing education credits or } \\
\text { Maintenance of Certification }\end{array}$ & 49.2 & 48.6 & 48.7 & 50.0 & .98 \\
\hline $\begin{array}{l}\text { Opportunity to shape research questions, } \\
\text { projects, and journal articles }\end{array}$ & 35.1 & 28.6 & 54.1 & 32.1 & .02 \\
\hline Academic advancement/recognition & 36.2 & 41.4 & 27.0 & 35.9 & .34 \\
\hline
\end{tabular}

Values provided as percent. Bolded values indicate statistical significance.

Clinical and Translational Science Award, established the Greater Rochester PBRN (GR-PBRN). Before engaging practices in PBRN-related research, we surveyed physicians about practicebased research to assess factors that facilitate physician participation in practice-based research and to compare the perspectives of internists, family physicians, and pediatricians.

\section{Methods \\ Setting}

The study was conducted in Monroe County, New York, which includes the city of Rochester and the surrounding suburban and rural communities.

\section{Study Design}

We sent a confidential survey to all primary care physicians in Monroe County. We used multiple search strategies to identify physicians, including existing department lists, yellow pages listings, web sites of health systems, and publicly available lists from insurance providers. We called practices to confirm physician names and practice addresses, and we surveyed all physicians rather than a practice representative.

The questionnaire examined past experience with research and incentives that facilitate participation in practice-based research. We asked physicians to rate the incentives that were "most important of all" on a 4-point Likert scale, which we collapsed it into 2 categories.

\section{Analyses}

We performed descriptive analyses of the data and used $\chi^{2}$ and analysis of variance tests to compare responses among specialties.

\section{Results}

Response Rates and Demographic Characteristics

Of the 559 physicians for whom addresses were verified, 185 completed the survey (33\%): 70 of the 241 internal medicine (IM) physicians (29\%) responded; 37 of the 132 family physicians (FP; 29\%) responded; and 78 of the 186 pediatricians (42\%) responded. Seventy-four percent of respondents had participated in at least one research study during the past 5 years, including $67 \%$ of internists, $68 \%$ of family physicians, and $79 \%$ of pediatricians. Four percent of respondents' practices had participated in more than 10 studies.

\section{Perceived Incentives to Participating in Practice- Based Research}

Physicians were asked to what extent aspects of collaboration with academic researchers would be important to them and to rate the most important aspect. The 3 most frequently endorsed "important" items were the opportunity to enact quality improvement (78\%), contribution to clinical knowledge $(75 \%)$, and intellectual stimulation $(65 \%)$. These 3 items were also most frequently cited as "the most important of all." The 3 least frequently endorsed "important" items were recognition by patients (17\%), recognition by colleagues 
(21\%), and additional source of income $(30 \%)(\mathrm{Ta}-$ ble 1).

Significant differences among the primary care specialties were found in 2 aspects: (1) internists were more likely to endorse additional source of income as "important" and (2) family physicians were more likely to cite the opportunity to shape research questions, projects, and journal articles as "important."

\section{Discussion}

Our study noted high interest in practice-based research among physicians and a willingness to participate in research; key incentives were the potential for quality improvement, contribution to knowledge, and intellectual stimulation. These findings underscore the importance of conducting practice-based research that is clinically relevant to physicians, such as quality improvement studies or clinical projects with short-term practice benefits. ${ }^{5}$

Internists were significantly more likely to endorse "additional source of income" as an incentive than other family physicians or pediatricians. It is unclear whether this reflects a higher level of financial pressures endured by internists compared with other specialists or other factors. Overall, PBRNs will need to carefully assess local incentives to practice-based research and devote substantial efforts to understanding specialty differences if they are to include a broad spectrum of practices in their studies.
We thank the Steering Committee Members of the Greater Rochester Practice-Based Research Network: John Andolina, MD, Clinton Medical Associates; Philip Bonanni, MD, Unity Health; James L. Budd, MD, Twelve Corners Internal Medicine; John K. Chamberlain, MD, Ridgewood Med-Peds; John F. Cox III, MD, Clinton Medical Associates; Joseph A. DiPoala Jr., MD, Ridgeview Internal Medicine Group; Paul S. Frame, MD, Tri-County Family Medicine; Anne B. Francis, MD, Elmwood Pediatric Group; Raj B. Kachoria, MD, Kachoria Family Practice; Edward D. Lewis, MD, Lewis Pediatrics; Sanford J. Mayer, MD, Twelve Corners Pediatrics; Michael Nazar, MD, Unity Health; Betty Rabinowitz, MD, Clinton Medical Associates; and Heidi R. Zinkand, MD, Westside Health Services.

\section{References}

1. Simpson LA, Marshall R. Getting the evidence needed: a recent report from the Institute of Medicine. Ambul Pediatr 2008;8:147-9.

2. Szilagyi PG. Translational research and pediatrics. Acad Pediatr 2009;9:71-80.

3. Wasserman RC, Slora EJ, Bocian AB, et al. Pediatric research in office settings (PROS): a national practice-based research network to improve children's health care. Pediatrics 1998;102:1350-7.

4. Hickner J, Graham DG, Elder NC, et al. Testing process errors and their harms and consequences reported from family medicine practices: a study of the American Academy of Family Physicians National Research Network. Qual Saf Health Care 2008;17:194-200.

5. Mold JW, Peterson KA. Primary care practice-based research networks: working at the interface between research and quality improvement. Ann Fam Med 2005;3(Suppl 1):S12-20. 